\title{
TRATADOS INTERNACIONAIS EM MATÉRIA TRIBUTÁRIA E O ART.98 DO CODIGO TRIBUTÁRIO NACIONAL
}

\author{
INTERNATIONAL TREATIES IN TAX MATTERS AND ARTICLE \\ 98 OF THE NATIONAL TAX CODE \\ Paulo Roberto Lyrio Pimenta ${ }^{1}$
}

\begin{abstract}
Recebido em: 22/11/2017 Aceito em: 28/12/2017

p-pimenta@uol.com.br
\end{abstract}

Resumo: O presente artigo busca examinar os problemas proporcionados na aplicação do art. 98 do Código Tributário Nacional. Embora se trate de uma regra vigente há mais de meio século em nosso ordenamento, nem a doutrina nem a jurisprudência encontraram ainda soluções definitivas para uma interpretação desse dispositivo que se adeque com a sistemática prevista para os tratados internacionais na Constituição Federal de 1988. O artigo demonstrará que não existe hierarquia entre os tratados e a legislação infraconstitucional, segundo o modelo constitucional atualmente vigente. Por conseguinte, os tratados internacionais em matéria tributária não têm aptidão para revogar a legislação interna, veiculando, em verdade, norma especial, que afasta a eficácia da lei interna no que dispuser de forma contrária. Como não existe hierarquia, a legislação tributária posterior ao tratado poderá dispor de forma contrária. Apenas os atos infralegais estarão adstritos à observância de tratado anterior. Em qualquer caso, a norma do art. 98 do CTN poderá ser aplicada às duas modalidades de tratados, como já reconhece, inclusive, a atual jurisprudência do Supremo Tribunal Federal.

Palavras-chave: Art.98, CTN. Eficácia. Interpretação. Jurisprudência. Supremo Tribunal Federal.Tratados Internacionais.

\begin{abstract}
The paper deals with problems in the application of art. 98 of the National Tax Code. Although it is a rule that has been in force for more than half a century in our legal system, neither doctrine nor jurisprudence has found definitive solutions for an interpretation of this provision in accordance with the system provided for in international treaties in the 1988 Federal Constitution. There is no hierarchy between the treaties and the infraconstitutional legislation, according to the constitutional model. Consequently, international tax treaties do not have the capacity to repeal domestic legislation, in fact implying a special rule, which detracts from the effectiveness of domestic law to the contrary. As there is no hierarchy, the post-treaty tax legislation may have otherwise. Only the acts of infralegal law are bound to the observance of a previous treaty. In any case, the rule of art. 98 of the CTN can be applied to both modalities of treaties, as already recognized, including the current jurisprudence of the Federal Supreme Court.
\end{abstract}

Keywords: Art. 98. National Tax Code. Interpretation. Internacional Treaties.Supreme Court.

\section{INTRODUÇÃO}

Após mais meio de século de vigência em nosso ordenamento, a regra veiculada pelo art. 98 do Código Tributário Nacional ainda é objeto de muitas controvérsias, tanto no âmbito da doutrina quanto no da jurisprudência. Uma das razões da existência dessas divergências é a ausência de um exame detalhado por parte do Supremo Tribunal Federal, bem como pelo Superior Tribunal de Justiça, sobre a matéria.

O presente estudo busca encontrar soluções para os problemas gerados pela interpretação do mencionado dispositivo, que se harmonizem com a disciplina dada aos tratados internacionais por

\footnotetext{
${ }^{1}$ Universidade Federal da Bahia - UFBA - Salvador - Bahia - Brasil
} 
nosso ordenamento jurídico, mormente pelo texto da Constituição Federal. Seria possível mesmo afirmar que os tratados internacionais "revogam" a legislação interna? Há hierarquia entre os tratados e as leis tributárias infraconstitucionais? O conteúdo dos tratados vincula a legislação posterior? O art. 98 é aplicável apenas aos tratados-normativos?

Essas são as principais questões a serem enfrentadas no decurso do texto, o qual visa encontrar respostas que possibilitem a aplicação da regra referenciada sem violar o sistema traçado sobre a matéria pelo CTN.

\section{TRATADOS INTERNACIONAIS}

\subsection{Os tratados perante o Direito Internacional}

Não há consenso na doutrina quanto ao conceito de tratado. Defende-se que é um acordo formal celebrado entre pessoas jurídicas de direito internacional público e destinado a produzir efeitos jurídicos (REZEK, 2011, p.38). Outros defendem que se trata de um ato jurídico por meio do qual se manifesta o acordo de vontades entre sujeitos de direito internacional (ACCIOLY, 2012, p.158). Há, ainda, quem defenda uma ideia mais simples, enxergando os tratados como acordos de vontades de sujeitos de direito internacional, regidos por este ramo do direito (BAHIA, 2000, p.3). Em todo tratado existe, pelo menos, três elementos: a)a personalidade de direito internacional dos celebrantes; b) a manifestação de vontade; c) a forma escrita. Com base nesses elementos, pode-se conceituar os tratados como manifestações de vontade, formuladas por escrito, emitida por dois ou mais sujeitos de direito internacional público.

Dentre os traços utilizados para classificar os tratados, um dos mais tradicionais é o do objeto, que os separa em tratados normativos e contratuais. Por meio dos tratados-contratos as partes produzem normas jurídicas individuais e concretas, comprometendo-se ao cumprimento de uma série de obrigações (ex: acordos de comércio). Já os tratados normativos, são aqueles que veiculam normas gerais e abstratas (BAHIA, 2000, p.3). Em geral, os tratados normativos são multilaterais, sendo, pois, pactuados por vários países para estabelecer normas de direito internacional (ex: Convenção de Viena) (ACCIOLY, 2012, p.160). Essa separação, em verdade, é falha, pois todo tratado veicula uma norma jurídica. O que varia é a eficácia subjetiva da regra veiculada.

O procedimento de celebração dos tratados é regulado pela Constituição Federal, em nosso sistema jurídico. O art. 21, I estabelece que a União é competente para "manter relações com Estados estrangeiros e participar de organizações internacionais". Nesse caso, a União atua como pessoa representante do Estado brasileiro, da República Federativa do Brasil.

Quem tem competência para agir em nome da República Federativa do Brasil, celebrando os tratados, é o Presidente da República (CF, art. 84, VIII). É ele quem participa da primeira fase do procedimento visando à pactuação dos tratados, a qual termina com a autenticação, que consiste no 
ato por meio do qual as partes declaram que concluíram o acordo, estabelecendo o texto que será submetido à ratificação por outro órgão, no caso brasileiro, o Congresso Nacional (XAVIER, 1998, p.97). Esse órgão tem competência para "resolver definitivamente sobre tratados, acordos ou atos internacionais que acarretem encargos ou compromissos gravosos ao patrimônio nacional "(CF, art. $49, \mathrm{I})$.

No exercício dessa faculdade, caberá à Casa Legislativa referendar o tratado, que é uma autorização para o Presidente da República ratificar esse ato. O referendo não pode modificar o conteúdo do tratado, limitando-se a autorizar ou rejeitar a ratificação. Destarte, a participação do Congresso é meramente formal e externa, pois não interfere na cena diplomática, nem vincula o Presidente a concluir o tratado (XAVIER, 1998, p.98-99).

A autorização é expressa por meio do decreto legislativo. Uma vez autorizado pelo Congresso, o Presidente poderá ou não ratificar o tratado. A ratificação tem que ser expressa, assumindo a forma de um ato firmado pelo Presidente da República e referendado pelo Ministro das Relações Exteriores (REZEK, 2011, p.79). Geralmente existe um prévio entendimento diplomático programando a comunicação mútua, que é acompanhada pelos instrumentos documentais de ratificação (REZEK, 2011, p.79). Feita a ratificação, é realizada a promulgação, por meio do Decreto do Presidente da República. O Decreto noticia, dá publicidade quanto à existência do tratado, introduzindo-o no ordenamento jurídico, para que possa viger (XAVIER, 1998, p.98).

Prestados esses esclarecimentos, importa examinar as relações dos tratados com a ordem jurídica interna. Para alcançar esse desiderato, é importante ressaltar a existência de duas concepções: monista e dualista. Para o monismo, o direito é uma unidade, na qual se incluem o direito interno e o internacional. Vale dizer, os Estados reconhecem a vigência na ordem interna do direito internacional. Já para o dualismo, o direito interno e o internacional são dois sistemas distintos. Há uma diversidade de fontes do direito, razão pela qual a norma internacional não vigora na ordem interna antes de ser recepcionada pelo direito interno (XAVIER, 1998, p.101-102).

No ordenamento brasileiro, os tratados devem obedecer ao procedimento acima mencionado para serem incorporados ao direito interno. Resulta daí uma opção clara da Constituição de 1988 em favor do dualismo.

Não há necessidade de elaboração de uma lei para veicular o tratado. O tema já foi apreciado pelo Supremo Tribunal Federal, que firmou o entendimento de que as normas veiculadas pelo tratado têm aplicação imediata, após a aprovação pelo Congresso Nacional e posterior promulgação. ${ }^{2}$

\footnotetext{
2 STF, RE 71.154, Tribunal Pleno, Rel. Min. Osvaldo Trigueiro, DJ 04/08/1971. Em seu voto, o Ministro Relator asseverou o seguinte: "Não me parece curial que o Brasil firme um tratado, que esse tratado seja aprovado definitivamente pelo Congresso nacional, que em seguida seja promulgado, e apesar de tudo isso, sua validade fique dependendo de novo ato do Poder Legislativo. A prevalecer esse critério, o tratado, após sua ratificação, vigoraria apenas no plano internacional, porém não no âmbito do direito interno, o que colocaria o Brasil na privilegiada posição de poder exigir a observância do pactuado pelas outras partes contratantes, sem ficar sujeito à obrigação recíproca.
} 
Destarte, a incorporação do tratado ao direito interno deve seguir tão-somente o procedimento previsto pela Constituição Federal, sem a necessidade de elaboração de outra fonte do direito pelo Poder Legislativo, visando veicular as normas previstas pelo tratado.

Quanto à hierarquia dos tratados no ordenamento brasileiro, num primeiro momento a jurisprudência do Pretório Excelso, construída na primeira metade do século passado, posicionava-se no sentido da inadmissão de hierarquia dos tratados perante a Constituição Federal, aceitando, por outro lado, a superioridade destes em face da legislação infraconstitucional. ${ }^{3}$ Esse panorama foi modificado no julgamento do mais importante precedente sobre a matéria, o Recurso Extraordinário № 80.004. Nesse julgado, o Ministro Relator, Xavier de Albuquerque, defendeu a superioridade dos tratados sobre a lei interna. Porém, esse posicionamento foi vencido, prevalecendo o entendimento do Ministro Cunha Peixoto no sentido de que os tratados são incorporados no ordenamento brasileiro como lei infraconstitucional, podendo, inclusive, ser revogados como qualquer outra lei. ${ }^{4}$

O status de lei, reconhecido pela jurisprudência do Pretório Excelso aos tratados, a partir desse julgado, foi ratificado em diversas decisões posteriores. ${ }^{5} \mathrm{Em}$ julgado recente esse posicionamento foi mantido, esclarecendo a Corte, ainda, que os tratados não podem regular matéria objeto de lei complementar. 6

\subsection{Os Tratados sobre direitos humanos}

A doutrina diverge sobre o status dos tratados internacionais que versam sobre direitos humanos, podendo ser identificadas as orientações que defendem as seguintes posições: a) natureza supraconstitucional; b) caráter de norma constitucional; c)status de lei ordinária; d)natureza supralegal (MENDES; COELHO; BRANCO, 2009, p.691).

No ordenamento brasileiro, a questão restou pacificada com a promulgação da Emenda Constitucional $n^{\circ} 45$, de 2004, que inseriu o parágrafo terceiro no art. $5^{\circ}$, estabelecendo que "os tratados e convenções internacionais sobre direitos humanos que forem aprovados, em cada Casa do Congresso Nacional, em dois turnos, por três quintos dos votos dos respectivos membros, serão equivalentes às emendas constitucionais".

Destarte, a Constituição passou a admitir que uma determinada classe de tratados, com conteúdo específico, possa ter natureza de Emenda Constitucional, desde que aprovados pelo procedimento previsto no art. 60, após o advento da Emenda epigrafada. Para os tratados aprovados anteriormente, o status é de lei ordinária, comum aos demais tratados.

A objeção seria ponderável se a provação do tratado estivesse confiada a outro órgão, que não o Congresso Nacional. Mas, se a aprovação é ato do mesmo poder elaborador do direito escrito, não se justificaria que, além de solenemente aprovar os termos do tratado, o Congresso Nacional ainda tivesse de confirmá-los, repetitivamente, em novo diploma legal" (STF, RE 71.154, Tribunal Pleno, DJ 04/08/1971, p. 283).

${ }^{3}$ Nesse sentido: STF, RE 58.713, 3a Turma, Rel. Min. Hermes Lima. DJ 30/09/1966.

${ }^{4}$ STF, RE 80.004, Tribunal Pleno, Rel. Min. Cunha Peixoto, DJ 29/12/1977.

${ }^{5}$ STF, HC no 72.131, Tribunal Pleno, Rel. Min. Marco Aurélio, DJ 01/08/2003; HC no 81319, Tribunal Pleno, Rel. Min. Celso de Mello, DJ 19/08/2005.

${ }^{6}$ STF, ADIMC no 1.480, Tribunal Pleno, Rel.Min. Celso de Mello, DJ 18/05/2001. 
Assim, no modelo atual os tratados internacionais têm como regra geral a natureza de lei ordinária, como exceção, natureza de norma constitucional. O que os diferencia é o respectivo conteúdo e procedimento de aprovação.

Na jurisprudência do Supremo Tribunal Federal esse tema já foi debatido, sem o exame das modificações perpetradas pela Emenda Constitucional ํㅡ 45/2004. No julgamento do RHC no 79.785 , no voto do Ministro Carlos Mário Velloso foi mencionada a possibilidade de que os tratados sobre direitos e garantias fundamentais apresentassem o caráter "supralegal". 7 Posteriormente, a Corte se posicionou em duas oportunidades no sentido de que os tratados que cuidam da proteção dos direitos humanos paralisam a eficácia de toda e qualquer disciplina constitucional, apresentando, destarte, o caráter supralegal. ${ }^{8}$ Convém observar, no entanto, que esse posicionamento não é tranquilo no âmbito da Corte, pois alguns Ministros defendem que esses tratados, mesmo celebrados antes da EC no 45/2004, apresentam natureza de norma constitucional material. ${ }^{9}$

Os tratados a que se refere 0 at. $5^{\circ}$, $3^{\circ}$ ํ poderão alcançar o direito tributário, pois ao versarem sobre direitos humanos, poderão regular alguma matéria que afete os contribuintes. Nada impede, por exemplo, que sejam celebrados tratados que, para implementar a isonomia, vedem a discriminação tributária entre nacionais e estrangeiros. Em tais situações, os tratados internacionais terão, na órbita tributária, natureza de norma constitucional, desde que celebrados após 2004, não se submetendo ao regramento do art. 98 do CTN, adiante examinado.

\section{OS TRATADOS INTERNACIONAIS EM MATÉRIA TRIBUTÁRIA}

\subsection{Os tratados como fontes do Direito Tributário}

Os tratados representam uma das principais fontes do Direito Tributário.

Há uma série de tratados internacionais celebrados fora da órbita tributária, os quais, contudo, veiculam, em caráter acessório, disposições tributárias. Exemplo: uma convenção sobre comércio internacional que contemple uma isenção fiscal para determinados produtos.

Além desses, há tratados especificamente tributários, pois apresentam um conteúdo tipicamente tributário. São aqueles celebrados, em primeiro lugar, para evitar, atenuar ou eliminar a possibilidade de pluritributação, que consiste no concurso de pretensões impositivas oriundas de diversos países (TORRES, 2001, p.380). Não se trata de um ato ilícito, não sendo proibida por nenhum ordenamento. Além disso, os tratados podem ser firmados para evitar a evasão fiscal ou buscando regular a colaboração administrativa entre países (XAVIER, 1998, p.87-88).

A múltipla incidência tributária pode surgir diante da possibilidade de que um mesmo ato ou fato possa ser atingido por mais de uma imposição, de mais de um país, obviamente. Com isso,

\footnotetext{
${ }^{7}$ STF, RHC no 79.785, Tribunal Pleno, Rel. Min. Sepúlveda Pertence, DJ 22/11/2002.

${ }^{8}$ RE no 349.703, Tribunal Pleno, Rel. para o Acórdão, Min. Gilmar Mendes, DJ 04/06/2009; RE no 466.343, Tribunal Pleno, Rel. Min. Cezar Peluso, DJ 04/06/2009.

${ }^{9}$ Defenderam esse posicionamento os Ministros, já aposentados, Cezar Peluso (STF, RE no 349.703, Tribunal Pleno, DJ 03/12/2008), Eros Grau e Ellen Gracie (STF, HC no 87585, Tribunal Pleno, DJ 25/06/2009). Atualmente, a tese é esposada pelo Ministro Celso de Mello (STF, RE no 349.703).
} 
busca-se evitar que um mesmo sujeito possa ter a sua manifestação de riqueza gravada por tributos de diferentes países, comprometendo a capacidade contributiva. Destarte, a dupla imposição internacional é a possibilidade de dupla incidência, sobre um mesmo fato gerador, no mesmo período de tempo, de regras jurídicas tributárias de mais de um país.

Para evitar ou solucionar essa problemática, os países podem adotar medidas unilaterais ou bilaterais. As medidas unilaterais são as regras veiculadas pelo ordenamento jurídico de determinada nação, visando evitar a dupla tributação internacional. Como exemplos dessas medidas, pode-se citar a isenção, a redução de alíquota e a dedução de impostos recolhidos no exterior, da base de cálculo (GRUPENMACHER, 1999, p.94-95). Os tratados internacionais representam a modalidade bilateral mais efetiva de medida adotada para evitar a possibilidade de dupla imposição, à medida que veiculam dispositivos para evitar a ocorrência desse tipo de situação.

\subsection{A controversa interpretação do art. 98 do CTN}

Diante da celebração de um tratado internacional com repercussão na esfera tributária, questiona-se qual a sua eficácia no âmbito do direito interno, em face da possibilidade de existência de um conflito (antinomia) entre a lei interna e o tratado. Sobre o assunto, pode-se identificar na doutrina algumas posições.

Para um primeiro grupo de doutrinadores, liderados por Alberto Xavier, os tratados têm hierarquia em face da legislação interna, assegurada pelo art. $5^{\circ}, \S^{\circ}{ }^{\circ}$ da Constituição Federal. Para ele, esse dispositivo constitucional reconhece a existência de direitos subjetivos decorrentes de tratados internacionais, não previamente convertidos em leis internas. De outro lado, para o autor, o art. 109, III da CF reconhece que os juízes federais detém competência para examinar direitos subjetivos emergentes diretamente dos tratados. Assim, os tratados são recebidos pelo ordenamento jurídico como tal, e não como lei infraconstitucional, não podendo ser revogados ou denunciados pela lei ordinária (GRUPENMACHER, 1999, p.109-110). Por conseguinte, em face de uma antinomia normativa, as disposições veiculadas pelos tratados sempre devem prevalecer sobre o disposto na lei interna.

Outro segmento doutrinário sustenta que o critério a ser utilizado para a resolução da antinomia em epígrafe é o princípio "pacta sunt servanda", segundo o qual o Estado signatário de um tratado tem que observar as obrigações por ele assumidas, sob pena de ser responsabilizado na órbita internacional. Por conseguinte, o tratado sempre deverá prevalecer sobre o direito interno, por se tratar de norma de "sobredireito" (GRUPENMACHER, 1999, p.110-111).

Posição mais recente é defendida por Luis Eduardo Schoueri(2011, p.96-99) Para ele, não se trata de um problema de hierarquia, mas de competência. Os tratados são instrumentos que definem a jurisdição nacional. Logo, não entram em conflito com o direito interno, pois estabelecem limites a este. Como no âmbito internacional o Estado não detém jurisdição, suas normas internas não podem ser aplicadas, conseguintemente. 
O tema é disciplinado no direito brasileiro pelo art.98 do CTN, que estabelece o seguinte: "Art. 98. Os tratados e as convenções internacionais revogam ou modificam a legislação tributária interna, e serão observados pela que lhes sobrevenha". ${ }^{10}$

Interpretando-se esse dispositivo, infere-se, inicialmente, que não se trata, tecnicamente, de uma revogação do tratado à legislação interna. A lei que estiver em conflito com o tratado continua a ser aplicada em ouras situações, por ele não alcançadas. Logo, a sua vigência não é atingida pelo tratado. O problema, portanto, é de eficácia, não de vigência.

Partindo-se dessa premissa, verifica-se que o tratado veicula uma norma especial, que deverá prevalecer sobre a norma geral, prevista na legislação interna. Vale dizer, em relação aos demais países, que não firmaram o tratado, a lei interna continua a prevalecer. No entanto, a norma especial, prevista no tratado, irá afastar a aplicação da lei interna na situação específica prevista pelo acordo internacional. Assim, por exemplo, se a lei estabelecer a tributação de determinado negócio jurídico e o tratado firmado pelo Brasil com o país " $X$ " conceder uma isenção a esse acordo, o tributo será exigido em outras operações, exceto em relação àquelas que alcancem o país " $X$ ". Não existirá, portanto, nem revogação nem derrogação. Apenas a eficácia da norma interna será afastada nos casos regulados pelo tratado. Assim, a norma interna deixará de ser aplicada integralmente. Esse parece ser o melhor posicionamento da doutrina sobre a matéria, que consagra uma exegese bastante razoável do dispositivo em tela. ${ }^{11}$

$\mathrm{Na}$ jurisprudência do Supremo Tribunal Federal, anterior à vigência do CTN, prevalecia o posicionamento de que havia primazia dos tratados sobre a lei infraconstitucional. ${ }^{12}$ Posteriormente, a Corte fez apenas uma referência ao art. 98 do CTN no julgamento do Recurso Extraordinário no 80.004 - que versava sobre a aplicação da Lei Uniforme de Genebra em nosso ordenamentooportunidade em que defendeu que esse dispositivo se aplica apenas aos tratados-contratos, e não aos tratados normativos, todavia, sem examiná-lo de forma mais profunda. ${ }^{13}$ Recentemente, porém,

\footnotetext{
${ }^{10}$ Gilberto de Ulhoa Canto, um dos integrantes da Comissão que elaborou o anteprojeto do CTN, explica a razão da previsão contida no art. 98: "O artigo consagrou um princípio que ao tempo do Código era tranquilamente aceito pela jurisprudência dos nossos tribunais". ( Legislação tributária, sua vigência, sua eficácia, sua aplicação, interpretação e integração. Revista Forense, v. 267, julho/agosto 1979, RJ, Forense, 1979, p.27).

${ }^{11}$ Defende essa posição Luciano Amaro (2010, p.202-205) e Betina Treiger Grupenmacher (1999, p.114), dentre outros.

12 RE 113.156, 2a Turma, Rel. Min. Carlos Madeira, DJ 30/06/1987; RE 113.150, 2a Turma, Rel. Min. Carlos Madeira; RE 114.950, 1a Turma, Rel. Min. Moreira Alves, DJ 20/11/1987; RE 76099, 1aㅡ Turma, Rel. Min. Rodrigues Alckmin, DJ 07/04/1975; RE 87.704, 2a Turma, Rel. Min. Leitão de Abreu, DJ 30/11/1979; RE 92.982, 1a Turma, Rel. Min. Rafael Mayer, DJ 21/10/1980; . RE 97.088, 1a Turma, Rel. Min. Oscar Correa, DJ 03/12/1982.

${ }^{13} \mathrm{O}$ voto do Relator para o Acórdão, Ministro Cunha Peixoto, explica os fundamentos adotados pelo STF para sustentar que o art. 98 é aplicável apenas aos tratados contratuais, verbis: "Como se verifica, o dispositivo refere-se a tratados e convenções. Isso, porque os tratados podem ser normativos, ou contratuais. Os primeiros traçam regras sobre pontos de interesse geral, empenhando o futuro pela admissão de princípio abstrato, no dizer de Tito Fulgêncio. Contratuais são acordos entre governantes acerca de qualquer assunto. $O$ contratual é, pois, título de direito subjetivo.

Daí o art. 98 declarar que tratado ou convenção não é revogado por lei interna. E que se trata de um contrato, que deve ser respeitado pelas partes". A análise desse voto conduz-nos à ilação de que o princípio da força obrigatória dos contratos foi o fundamento utilizado pela Corte para justificar a aplicação do art. 98 apenas aos tratados contratuais" (p.954-955).
} 
esse posicionamento foi abandonado, entendendo o Tribunal que o dispositivo também alcança os tratados normativos. ${ }^{14}$

A jurisprudência do Superior Tribunal de Justiça, influenciada pela antiga jurisprudência do STF, também diferencia tratados normativos (tratados-leis) de tratados contratuais (tratadoscontratos) para interpretar o art. 98 do CTN. A Corte entende que os tratados-leis prevalecem sobre a legislação interna, o que não ocorre com os tratados contratuais. ${ }^{15}$ Essa diferenciação não encontra fundamento do ordenamento jurídico. Outrossim, o art. 98 não estabelece qualquer distinção quanto ao tipo de tratado a que se refere, não cabendo ao intérprete fazê-lo, por conseguinte.

Outro problema relativo à eficácia dos tratados é a necessidade ou não de sua observância pela legislação interna posterior, considerando que o art. 98 estabelece expressamente que os tratados serão observados pela legislação "que Ihes sobrevenha". Investiga-se, nesse particular, a possibilidade de a lei revogar tratado em vigor. O problema também divide a doutrina. Parcela minoritária defende que não é possível ao legislador infraconstitucional revogar nem modificar as regras veiculadas pelo tratado e incorporadas ao direito interno. Isso porque o procedimento de celebração dos tratados pressupõe a participação conjunta dos Poderes Executivo e Legislativo, não sendo admissível que a revogação ou denúncia do tratado ocorra sem uma colaboração conjunta desses Poderes (XAVIER, 1998, p.115-116).

Não nos parece que este argumento possa ser aceito em defesa dessa tese. Em verdade, no procedimento de elaboração das leis também existe uma participação de dois poderes: o Legislativo, na fase de iniciativa, discussão e votação do projeto de lei, e do executivo, na iniciativa e na sanção. Logo, atuação conjunta existe tanto na aprovação dos tratados quanto na elaboração de uma lei. De outro lado, não se pode admitir que a Constituição Federal tenha previsto em seu art. $5^{\circ}, 2^{\circ}$ uma superioridade hierárquica dos tratados. $\mathrm{O}$ objetivo visado pelo constituinte com a introdução desse dispositivo foi o de admitir que os direitos e garantias veiculados pelos tratados também pudessem integrar o ordenamento, todavia, não em posição de superioridade hierárquica. $O$ enunciado constitucional nada dispôs sobre esse tema. Ademais, não se pode admitir que a celebração de um tratado (ato jurídico entre dois países) retire do legislador a liberdade para editar lei nova. Aceitar o entendimento contrário poderia importar na paralisação das atividades legislativas sobre todas as matérias veiculadas pelos tratados, o que não é previsto em nosso sistema jurídico.

Esse tema também foi examinado pelo Supremo Tribunal Federal no leading case sobre os tratados, porém não em matéria tributária. Na oportunidade, duas posições se formaram na Corte. A primeira, defendida pelo Ministro Leitão de Abreu, rejeitava a possibilidade de revogação do tratado internacional pela lei. Para ele, em tais situações, a lei afasta a aplicação da norma convencional. ${ }^{16}$

\footnotetext{
${ }^{14}$ STF, RE 90.824, Tribunal Pleno, Rel. Min. Moreira Alves, DJ 19/09/1980. Nesse julgamento, o Ministro Relator asseverou que "em matéria tributária, independentemente da natureza do tratado internacional, se observa o princípio contido no artigo 98 do Código Tributário Nacional".(p.447)

${ }^{15}$ STJ, RESP no 426.945, 1ạ Turma, Rel. Min. José Delgado, DJ 22/06/2004.

${ }^{16}$ Calha aqui a transcrição parcial do brilhante voto do Ministro Leitão de Abreu: "A orientação, que defendo, não chega a esse resultado, pois, fiel à regra de que o tratado posui forma de revogação própria, nega que este seja, em sentido próprio, revogado pela lei. Conquanto não revogado pela lei, que a incidência das normas jurídicas constantes do tratado é obstada pela aplicação, que os tribunais estão obrigados a fazer, das normas legais com aqueles conflitantes. Logo, a lei posterior, em tal caso, não revoga, em sentido técnico, o tratado,
} 
De outro lado, uma segunda corrente - vencedora no julgamento- , liderada pelo Ministro Relator, Cunha Peixoto e seguida pelos Ministros Cordeiro Guerra e Rodrigues Alckmin, defendeu a possibilidade de revogação da lei por outro diploma legal, baseada nos seguintes argumentos: a)se fosse admitida a impossibilidade de revogação, a lei decorrente do tratado seria transformada em uma super-lei, superior até mesmo à Constituição; b)não há na Constituição dispositivo que impeça um membro do Congresso de apresentar projeto de lei que revogue, tácita ou expressamente, uma lei oriunda de um tratado; c) não há na Constituição dispositivo que declare ser irrevogável uma lei positiva por ter sido oriunda de um tratado; d) seria inconstitucional uma lei que só pudesse ser revogada pelo Chefe do Poder Executivo, por meio da denúncia do Tratado; e)o único efeito da recepção do direito internacional pelo direito interno é o de dar força de lei às normas assim incorporadas à legislação; f)os tratados valem como lei e nesta qualidade serão aplicados pelos tribunais, da mesma maneira, na mesma extensão e com a mesma obrigatoriedade do direito interno; g)a Constituição confere competência ao STF para declarar a inconstitucionalidade de tratado ou de lei, em pé de igualdade, sem dar ao tratado internacional forma superior à da lei; h)a denúncia é o meio próprio de revogar um tratado internacional no campo do direito interno; i)a Constituição não confere aos tratados hierarquia sobre as leis ulteriores, tornando-as inválidas se thes forem contrárias; j) diante da ausência de uma norma constitucional que estabeleça restrição ao Poder Legislativo quanto à edição de leis internas contrárias a tratados, enquanto não forem estes denunciados, princípios doutrinários não justificam o primado destes. Admite-se, portanto, que a lei superveniente possa dispor de forma contrária ao tratado. Em julgado recente ratificou-se esse posicionamento. ${ }^{17}$

Como explicar, diante desse quadro, a cláusula final do art. 98, no sentido de que os tratados serão ser observados pela legislação "que Ihes sobrevenha"? Não se pode admitir que a lei complementar pretendeu com isso estabelecer uma hierarquia dos tratados em face da lei infraconstitucional. Essa interpretação conduziria ao reconhecimento da inconstitucionalidade do dispositivo, pois a suposta hierarquia só pode ser prevista pela Constituição Federal, o que inocorreu.

Partindo-se da premissa que a interpretação deve buscar um sentido que possibilite a convivência do texto com o plano constitucional (interpretação conforme a Constituição), parece-nos que uma possibilidade interpretativa bastante razoável é admitir que a legislação que deverá observar os tratados deve ser a legislação infralegal, os atos administrativos. Quando o legislador utilizou a expressão "legislação tributária interna", na segunda parte do art. 98, não o fez como sinônimo de "legislação tributária", prevista pelo art.96. Por conseguinte, não há impedimento à elaboração de lei que disponha em sentido contrário ao do tratado. Nesse caso, a norma legal, por ser especial, será aplicada, não se tratando de típico caso de revogação. Contudo, os decretos e as normas

senão que lhe afasta a aplicação. A diferença está em que, se a lei revogasse o tratado, este não voltaria a aplicar-se. Na parte revogada, pela revogação pura e simples da lei dita revogatória. Mas, como, a meu juízo, a lei não o revoga, mas simplesmente afasta, enquanto em vigor, as normas do tratado com ela incompatíveis, voltará ele a aplicar-se, se revogada a lei que impediu a aplicação das prescrições nele consubstanciadas". (STF, RE 80.004, p.984-985)

17 STF, ADIMC 1.480, Tribunal Pleno, Rel Min. Celso de Mello, DJ 18/05/2001. 
regulamentares não podem dispor em sentido contrário ao dos tratados, pois, na qualidade de atos de aplicação da lei, estarão adstritos ao seu cumprimento.

\subsection{Os tratados internacionais e a concessão de isenção de tributos estaduais e municipais}

A doutrina nacional discute, ainda, se os tratados internacionais podem conceder isenções de tributos estaduais ou municipais. Uma primeira linha de posicionamento se baseia no art. 151, III da Constituição Federal, que veda que a União conceda isenções de tributos estaduais ou municipais. Outro argumento utilizado é a incidência do art. 150,§6ํำ da CF, inserido pela Emenda à Constituição n 03/1993, segundo o qual "qualquer subsídio ou isenção, redução de base de cálculo, concessão de crédito presumido, anistia ou remissão, relativos a impostos, taxas ou contribuições, só poderá ser concedido mediante lei específica, federal, estadual ou municipal, que regule exclusivamente as matérias acima enumeradas ou o correspondente tributo ou contribuição, sem prejuízo do disposto no art. $155, \S 2^{\circ}$, XII, g”. Por conseguinte, os tratados não poderiam veicular norma de desoneração de tributo estadual ou municipal.

É importante traçar, em primeiro lugar, uma distinção entre a União, como pessoa jurídica de direito internacional, ou seja, como representante da República Federativa do Brasil, e a União como pessoa jurídica de direito público interno. A norma do art. 151, III da Constituição Federal veicula uma vedação à União, como pessoa de direito público interno (ordem jurídica parcial), e não à União, como pessoa de direito internacional.

Os tratados internacionais são celebrados pela União representando o Estado brasileiro. Os Estados e os Municípios não detêm soberania, logo, não são pessoas jurídicas de direito internacional. Portanto, não podem firmar tratados internacionais. O tratado, destarte, não se limita à esfera federal, e sim a todo o território da Federação. Ele alcança a ordem jurídica total (Estado Federal), e não a União (ordem jurídica parcial). Sendo assim, os tratados não são alcançados pela vedação constitucional referenciada.

De igual modo, a previsão do art. 150, $2^{\circ}$ da CF, se refere aos entes federados como pessoas jurídicas de direito público interno. Logo, não tem qualquer relação com a celebração de tratados internacionais, pois em tal hipótese só a União atua, e como representante do Estado brasileiro, vale reafirmar.

Por tais motivos, o tratado pode dispor sobre tributos estaduais ou municipais, sem que isso importe em burla de qualquer dispositivo constitucional.

Em tais situações, a norma do tratado irá prevalecer sobre a lei estadual ou municipal.

\section{CONCLUSÕES}

Em face das razões expostas, pode-se observar que um leque grande de tratados internacionais atinge direta ou indiretamente a órbita tributária. Os tratados que apresentam o conteúdo tipicamente tributário buscam principalmente eliminar ou atenuar a pluritributação.

A principal questão que se deve enfrentar é, em primeiro lugar, o da hierarquia desses instrumento normativos, não podendo ser aceita a corrente que defende a superioridade dos tratados internacionais em face das leis infraconstitucionais. 
Estabelecida essa premissa, cabe ressaltar que o leading case do Supremo Tribunal Federal sobre a relação entre os tratados e a legislação infraconstitucional, Recurso Extraordinário no 80.004, não analisou de forma detalhada o art. 98 do CTN, regra elaborada para tentar resolver o tema da eficácia dos tratados diante da legislação interna.

A melhor interpretação para esse dispositivo é a que sustenta que os tratados internacionais veiculam uma norma especial, afastando, no que dispuserem, a legislação interna. Não se trata, pois, nem de revogação nem de derrogação. O problema é de paralisação parcial da eficácia da lei interna.

Quanto à necessidade ou não de observância pela legislação infraconstitucional posterior da norma veiculada pelo tratado eventualmente celebrado, a cláusula final do art. 98 deve ser interpretada como uma necessidade de observância pela legislação infralegal do mandamento contido nos tratados.

Em qualquer caso, deve-se admitir que o art. 98 pode ser aplicados às duas modalidades de tratados: tratados-contratos e tratados-leis.

\section{REFERÊNCIAS}

ACCIOLY, Hildebrando; NASCIMENTO, G.E; CASELLA, Paulo Borba. Manual de Direito Internacional Público, 20ªed. São Paulo, Saraiva, 2012.

AMARO, Luciano. Direito Tributário Brasileiro, 16ª ed. São Paulo, Saraiva, 2010.

CANTO, Gilberto de Ulhoa. Legislação tributária, sua vigência, sua eficácia, sua aplicação, interpretação e integração. Revista Forense, v. 267, julho/agosto 1979, Rio de Janeiro, Forense, 1979, p.27-35.

BAHIA, Saulo Casali. Tratados Internacionais no Direito Tributário. Rio de janeiro, Forense, 2000.

GRUPENMACHER, Betina Treiger. Tratados Internacionais em Matéria Tributária e Ordem Interna. São Paulo, Dialética, 1999.

MACHADO, Hugo de Brito. Tributação no Mercosul. MARTINS, Ives Grandra da Silva. Tributação no Mercosul, 2ª̃ed., São Paulo, RT, p.83-95.

MENDES, Gilmar; COELHO, Inocêncio Mártires; BRANCO, Paulo Gustavo Gonet. Direito Constitucional, $2^{2}$ ed. São Paulo Saraiva, 2008.

REZEK, Francisco. Direito Internacional Público, 13ª̣ed. São Paulo, Saraiva, 2011.

SCHOUERI, Luis Eduardo. Direito Tributário, 3ª ed. São Paulo, Saraiva.2013.

TORRES, Heleno Taveira. Pluritributação Internacional sobre as Rendas de Empresas. São Paulo, RT, 2001.

XAVIER, Alberto. Direito Tributário Internacional do Brasil, 4ªed. Rio de janeiro, Forense, 1998.

\section{COMO CITAR ESSE DOCUMENTO:}

PIMENTA, Paulo Roberto Lyrio. Tratados internacionais em matéria tributária e o art.98 do codigo tributário nacional. Revista do Direito, Santa Cruz do Sul, v. 3, n. 53, dez. 2017. ISSN 1982-9957. Disponível em: <https://online.unisc.br/seer/index.php/direito/article/view/11368>. Acesso em: . doi:http://dx.doi.org/10.17058/rdunisc.v3i53.11368. 